\title{
Prática de ensino e estágio supervisionado na formação
}

\section{do professor de matemática}

\author{
Rosinete Gaertner \\ Universidade Regional de Blumenau \\ Departamento de Matemática \\ gaertner@furb.br \\ Vanessa Oechsler \\ Universidade Regional de Blumenau - FURB \\ ETEVI \\ vanessa.oe@gmail.com
}

Resumo: $O$ artigo apresenta a trajetória histórica da prática de ensino e estágio supervisionado na legislação da educação brasileira. Busca ainda compreender as mudanças ocorridas no currículo e no papel da prática de ensino e estágio supervisionado na formação de professores de Matemática nos últimos quarenta anos, tendo por base a análise das atividades de estágio no curso de Matemática da Universidade Regional de Blumenau, criado em 1968. Para isso, destaca fatos históricos e aspectos legais relativos à prática de ensino e a realização de estágio, apresenta e interpreta os dados da investigação de campo, concluindo ser fundamental a conexão entre teoria e prática, ação e reflexão na formação inicial do educador.

Palavras-chave: Prática de Ensino. Estágio. Legislação. Formação de Professores. Matemática.

\section{THE PRACTICE OF TEACHING AND SUPERVISED TRAINEESHIP IN THE FORMATION OF THE MATHEMATICS TEACHER}

\begin{abstract}
The article presents the historical trajectory of the practice of teaching and supervised traineeship in the legislation of Brazilian education. It also tries to understand the changes occurred in the curriculum and in the paper of the practice of teaching and supervised traineeship in the Math teachers' formation for the last forty years, taking as a base the analysis of the activities of traineeship in the course of Mathematics at the Regional University of Blumenau, created in 1968. In order to do so, we detach historical facts and legal aspects related to the practice of teaching and the realization of traineeship, it presents and interprets the data of the field investigation, concluding that it is fundamental the connection between theory and practice, action and reflection in the initial formation of the educator.
\end{abstract}

Keywords: Practice of Teaching. Traineeship. Legislation. Teachers' Formation. Mathematics 


\section{Introdução}

A formação de professores no Brasil tem suscitado pesquisas diversas e discussões importantes em encontros e congressos. A questão é ampla, envolvendo as dimensões humanas, educacionais, técnicas, sociais, políticas e econômicas. Este trabalho objetiva focalizar um dentre tantos temas referentes à formação de professores: o objeto da prática de ensino e do estágio supervisionado.

Atualmente, a legislação educacional brasileira atende as orientações de estudiosos que defendem a necessidade de unidade entre a teoria e a prática. Mas como isso tem sido considerado no interior dos cursos de licenciatura? Será que ela ocorre atualmente? Esses questionamentos orientaram a realização de investigação, que teve por base os resultados de pesquisa desenvolvida junto ao curso de Matemática da Universidade Regional de Blumenau, criado em 1968. Traçando um relato da trajetória histórica da prática de ensino e estágio supervisionado, buscou-se compreender as mudanças ocorridas no currículo e no papel da prática de ensino e estágio supervisionado na formação de professores de Matemática, bem como apontar sua necessidade nos cursos de licenciatura.

\section{Prática de ensino: uma breve retrospectiva histórica}

A história da educação no Brasil aponta para uma diversidade de políticas públicas, propostas pedagógicas e métodos de ensino. Também na formação de professores isto não foi diferente. Na época do Império já havia uma preocupação com a formação dos profissionais que iriam atuar como professores. Em 1820, com a instalação das primeiras escolas de ensino mútuo (Método Lancaster) ${ }^{1}$, surgiu a preocupação de preparar docentes com domínio do método. De acordo com Tanuri (2000, p.63) "essa foi realmente a primeira forma de preparação de professores, forma exclusivamente prática, sem qualquer base teórica".

Outras escolas destinadas à formação de professores, as Escolas Normais, que seguiram o modelo europeu, só foram implantadas após a reforma constitucional de 1834. A primeira escola normal brasileira foi criada em 1835, no Rio de Janeiro, tendo como objetivos habilitar as pessoas que se destinassem ao magistério do ensino primário e aos já professores que não tiveram uma formação adequada nas escolas de ensino mútuo. Como currículo para a formação docente constava apenas: ler e escrever, as quatro operações e proporções, a língua nacional, elementos de geografia e princípios de moral cristã. Entretanto, as escolas normais

\footnotetext{
${ }^{1}$ Este método residia na existência e no trabalho dos monitores, escolhidos entre os meninos mais habilitados, os quais recebiam instruções do mestre à parte. Na prática, esses monitores eram responsáveis pela instrução de uma decúria, ou seja, um grupo de 10 (dez) alunos.
} 
não tiveram o êxito esperado, formando poucos educadores e sofrendo diversas mudanças com o tempo em sua estrutura curricular, tendo sido agregada às suas matérias a disciplina de Pedagogia ou Métodos de Ensino, destinada à formação pedagógica dos professores, apesar de seu caráter rudimentar. Tal fato também poderia ser explicado pela falta de bibliografia pedagógica brasileira e pela falta de interesse da população pelo magistério, uma vez que a profissão oferecia poucos atrativos financeiros.

Nos primeiros anos da República, o descaso com o preparo profissional continuou, sendo que cada estado tinha o direito de reger a sua educação como bem o quisesse, o que acarretou grandes discrepâncias no ensino brasileiro. Somente no ano de 1937, com o regime do "Estado Novo", adotou-se uma política centralizadora, que se refletiu também na educação, promulgando-se uma lei comum a todos os estados da União. Assim, em 1939, foi publicado o Decreto Lei n.1190/39 que dispunha sobre a formação dos Cursos de Licenciatura, criando-se a Faculdade Nacional de Filosofia. Ainda dispunha o mesmo que, ao término do curso de bacharel, com duração de três anos, o acadêmico poderia optar por fazer mais um ano de curso de Didática para obter o título de licenciado, originando o conhecido sistema $3+1$ (três mais um). Tem-se, assim, uma separação entre o conteúdo estudado no curso de bacharel (onde eram vistas as disciplinas do conteúdo) e os métodos de ensino, que são vistos apenas no curso de Didática.

Durante este regime, a prática de diferentes leis em cada Estado foi discutida e com o Decreto Lei n.8530/46, que dispõe sobre a Lei Orgânica do Ensino Normal, fica estabelecido um "Currículo" único para todos os Estados. O Ensino Normal fica, portanto, dividido em dois ciclos: as Escolas Normais Regionais, com duração de quatro anos, e as Escolas Normais, com duração de três anos, onde havia uma "Estrutura Curricular" mais especializada para a formação docente e a disciplina de Prática de Ensino era estudada na $3^{\mathrm{a}}$ série do curso.

Em 1946, além da promulgação da Lei Orgânica do Ensino Normal, foram aprovados mais dois Decretos de Lei: Decreto-Lei n.9053, que dispunha sobre a não obrigatoriedade da Prática de Ensino constar no currículo do Curso de Didática, uma vez que era visto como um tema do programa e não como um componente do currículo mínimo exigido; e o Decreto-Lei 9092, que equipara a duração dos cursos de bacharelado e licenciatura.

Nas décadas de 1950 e 60 houve um movimento, no Brasil, que questionava os cursos de formação de professores. Quanto à prática de ensino, questionava-se a visão separada de método e conteúdo, pois os alunos aprendiam a imitar e reproduzir os modelos já existentes. De acordo com Barreiro e Gebran (2006, p.43) "Esperava-se que se ensinasse o professor a ensinar, conforme padrões consagrados". 
Após a Lei de Diretrizes e Bases da Educação de 1961, é promulgado, em 1962, o Parecer 292/62 do então Conselho Federal de Educação, que determina a obrigatoriedade da disciplina de prática de ensino e do estágio supervisionado, estipulando que o currículo mínimo para a licenciatura são as disciplinas do bacharelado e os estudos para o magistério através das disciplinas pedagógicas como: Psicologia da Educação, Didática e Elementos de Administração Escolar e Prática de Ensino (neste caso somente das matérias que se requer habilitação profissional). De acordo com Tanuri (2000, p.79), a didática e a prática de ensino eram diferenciadas: "aquela destinada a oferecer os princípios teóricos que fundamentam a prática de ensino e esta encarregada de oferecer as oportunidades para que o aluno vivenciasse os conhecimentos e as técnicas adquiridos durante o curso." Em 1969, o estágio supervisionado passa a ter o tempo mínimo de 5\% da carga horária do curso, conforme determinação do Parecer 627/69.

Neste contexto da história da educação é importante ressaltar que, em 1964, com o Golpe Militar, o Estado passa a adotar um modelo de educação tecnicista, que determina a obrigatoriedade do ensino de segundo grau profissionalizante. Esta situação acaba gerando novas Leis que vão dispor sobre o Magistério, agora com um caráter profissionalizante.

Com a Lei n.5962/71, verifica-se a extinção das Escolas Normais e a criação da habilitação profissionalizante de $2^{\circ}$ grau, denominada Habilitação Específica para o Magistério (HEM), onde os professores das séries iniciais cursariam três anos do curso, sendo apenas os dois últimos com disciplinas específicas para o magistério e, ao término deste, estariam habilitados para o exercício da profissão. Neste curso, a prática de ensino constava apenas no $3^{\circ}$ ano, ocorrendo o desenvolvimento de estágio junto a uma unidade escolar, realizadas as fases de observação, participação e regência de aulas.

Ao final do regime militar é promulgada a Lei 7044/82 que determina que o estágio nos cursos de licenciaturas continue como os do curso Magistério (fases de observação, participação e regência), não havendo preocupação com a articulação entre a realidade do ensino do $1^{\circ}$ grau e a formação do professor.

Em 1996, é promulgada a atual Lei de Diretrizes de Bases da Educação Nacional LDB n.9394/96 onde determina em seu artigo 62: "A formação de docentes para atuar na educação básica far-se-á em nível superior, em cursos de licenciatura, de graduação plena, em universidades e institutos superiores de educação."

Quanto à prática de ensino, prevê a atual LDB, em seu artigo 65: "A formação docente, exceto para a educação superior, incluirá prática de ensino de, no mínimo, trezentas horas". Ainda, com relação à discussão sobre "prática de ensino" a legislação através de 
parecer do CNE n.27/2001 ressalta que, a partir da data de sua publicação, o Estágio Obrigatório deve se desenvolver a partir do início da metade do curso.

No aspecto de formação docente, a Resolução CNE/CP 2, de 19 de fevereiro de 2002 dispõe em seu artigo primeiro sobre a carga horária dos cursos de Formação de Professores da Educação Básica, estabelecendo:

Art. $1^{\circ}$. A carga horária dos cursos de Formação de Professores da Educação Básica, em nível superior, em curso de licenciatura, de graduação plena, será efetivada mediante a integralização de, no mínimo, 2800 (duas mil e oitocentas) horas, nas quais a articulação teoria-prática garanta, nos termos dos seus projetos pedagógicos, as seguintes dimensões dos componentes comuns:

I - 400 (quatrocentas) horas de prática como componente curricular, vivenciadas ao longo do curso;

II - 400 (quatrocentas) horas de estágio curricular supervisionado a partir do início da segunda metade do curso;

III - 1800 (mil e oitocentas) horas de aulas para os conteúdos curriculares de natureza científico-cultural;

IV - 200 (duzentas) horas para outras formas de atividades acadêmico-científicoculturais.

Parágrafo único. Os alunos que exerçam atividade docente regular na educação básica poderão ter redução da carga horária do estágio curricular supervisionado até o máximo de 200(duzentas) horas.

É neste contexto que estão inseridos os cursos de licenciatura atualmente. Buscam os mesmos adaptarem-se à legislação vigente garantindo, ao mesmo tempo, qualidade na formação dos professores.

\section{Curso de matemática: abordagem sobre estágio e prática de ensino.}

No Brasil, até a criação da Faculdade de Filosofia, Ciências e Letras da Universidade de São Paulo (FFCL), em 1934, e da Faculdade Nacional de Filosofia integrante da Universidade do Brasil, no Rio de Janeiro (FNFi), em 1939, não havia preocupação com a preparação de professores de Matemática para o ensino secundário. "Os professores de Matemática que atuavam nas escolas secundárias obtiveram sua formação nas escolas politécnicas, escolas militares ou similares ou eram simplesmente leigos" (SILVA, 2000).

Na FFCL, o curso "Matemático" destinado à formação de professores tinha duração de três anos e compreendia basicamente as disciplinas de Geometria (analítica e projetiva), Análise Matemática, Física Geral e Experimental, Cálculo Vetorial e Mecânica Racional. Os bacharéis que se formassem no curso, recebiam licença para o magistério se completassem o curso de formação pedagógica no Instituto de Educação, com duração de um ano. 
Este ano de formação pedagógica não era bem visto pelos professores do curso "Matemático", conforme observado no depoimento de Castrucci sobre a orientação dada pelo professor Fantappiè2: "estuda Matemática, deixa de lado essas coisas de didática, porque didática só tem uma regra boa: saber a matéria, se você souber a matéria, o resto você é um artista e se for um mau artista será a vida toda, se for um bom artista será um bom professor. O resto põe tudo de lado" (Castrucci, apud Silva, 2000).

Nas escolas secundárias brasileiras, durante a década de 1940, poucos professores tinham a formação no curso de Matemática. Outros eram formados em faculdades de Filosofia ou ainda nas escolas politécnicas ou militares. Entretanto, a formação dos docentes atuantes na escola secundária em todas as áreas do ensino era precária, registra Mattos (1957), sendo que, em 1932 havia no país 342 estabelecimentos com 65000 alunos e em 1954 havia o registro de 1771 ginásios com rol de matrículas de 536000 alunos. Nos últimos 25 anos este crescimento foi de 500\%. Mas, apesar deste crescimento quantitativo, faltou à escola secundária o correspondente crescimento qualitativo, sendo o seu ponto mais crítico a precária formação do professorado. Apenas 16\% dos 40000 professores secundários tinham formação em faculdades de Filosofia, ou seja, $84 \%$ dos professores eram leigos autodidatas.

Estes dados desvelam que o cenário da educação superior continuava igual ao de antes da criação da FFCL.

Para suprir essa defasagem quanto à formação acadêmica dos professores, em 1953, é criada a Campanha de Aperfeiçoamento e Difusão do Ensino Secundário (CADES), que tinha dentre os seus objetivos promover a realização de cursos de aperfeiçoamento para professores. Aqueles que participavam destes cursos, após a aprovação de exames de suficiência, obtinham um registro de professores de ensino secundário e o direito de lecionar onde não houvesse disponibilidade de licenciados por faculdades de Filosofia. Estes cursos de preparação para o magistério, geralmente, tinham duração de um mês (janeiro ou julho) e abordavam aspectos pedagógicos e de conteúdos específicos das disciplinas que os professores iriam lecionar ou já lecionavam nas escolas secundárias.

Após 1964, há uma proliferação de novos cursos de ensino superior, inclusive na área de licenciatura. Neste período, em Santa Catarina, surgem faculdades com cursos de Licenciatura em Matemática. O primeiro destes cursos foi criado em 11 de maio de 1964, por ato da Congregação da Faculdade de Filosofia, Ciências e Letras, da Universidade Federal de Santa Catarina, em Florianópolis.

\footnotetext{
${ }^{2}$ Luigi Fantappiè (1901 - 1956), matemático italiano, nascido em Viterbo, na Itália. Chegou ao Brasil em 1934 com a missão de organizar os estudos matemáticos na recém criada FFCL na Universidade de São Paulo.
} 
No município de Blumenau, a mobilização para a criação do curso de graduação em Matemática e de outros da área de licenciatura começaria em 1967 com solicitação de um grupo de professores do ensino secundário junto às autoridades educacionais municipais.

\section{Estágio e prática de ensino no currículo do curso de matemática da FURB}

Em 20 de dezembro de 1967 é criada a Faculdade de Filosofia, Ciências e Letras de Blumenau, como unidade integrante da Fundação Universitária de Blumenau, tendo como diretor o professor Rivadávia Wollstein, único professor de Blumenau com graduação em Matemática, curso concluído na Pontifícia Universidade Católica do Rio de Janeiro.

Em 1968 é implantado o Curso de Matemática - Licenciatura Plena, sendo que os pretendentes a cursar Matemática prestaram vestibular no mês de maio e os aprovados iniciaram as atividades acadêmicas de forma intensiva, isto é, de junho a fevereiro, com o intuito de cumprir os créditos referentes a dois semestres letivos.

Em 1974, o Ministério da Educação e Cultura (MEC), através da Resolução n n 30/74 sustou a oferta dos cursos de licenciatura plena em Matemática, Física, Química e Ciências Biológicas, introduzindo o Curso de Ciências de $1^{\circ}$ grau, licenciatura curta. Aos egressos desse curso era oferecido reingresso à Universidade para complementação dos estudos em uma habilitação plena.

No período compreendido entre 1975 e 1986, a Universidade Regional de Blumenau $(\text { FURB })^{3}$ ofereceu regularmente o Curso de Ciências-Licenciatura de $1^{\circ}$ Grau e, quando havia demanda, a Complementação em Licenciatura Plena com Habilitação em Matemática. Em 1987, a FURB voltou a oferecer o Curso de Licenciatura Plena em Matemática.

Na grade curricular de 1968, a Prática de Ensino já aparece como uma disciplina obrigatória no curso de Matemática. E, desde o início o componente curricular Prática de Ensino do curso de licenciatura em Matemática sofreu alterações, como mostra o quadro seguir.

A carga-horária do componente curricular Prática de Ensino era determinada por normas legais vigentes no país nas diferentes épocas, o que justifica essas mudanças ocorridas na grade curricular do curso observadas no quadro acima. Questiona-se: o que o aumento da carga-horária contribuiu no aprendizado do estagiário?

A carga-horária do componente curricular Prática de Ensino era determinada por normas legais vigentes no país nas diferentes épocas, o que justifica essas mudanças ocorridas

\footnotetext{
${ }^{3}$ Em 24 de dezembro de 1968, a Fundação Universitária de Blumenau sofre profundas alterações em sua estrutura, transformando-se em Fundação Universidade Regional de Blumenau (FURB).
} 
na grade curricular do curso observadas no quadro acima. Questiona-se: o que o aumento da carga-horária contribuiu no aprendizado do estagiário?

Quadro: Alterações no componente curricular Prática de Ensino no curso de licenciatura em Matemática da FURB

\begin{tabular}{|c|c|c|c|}
\hline Ano & Nomenclatura & Semestre & $\begin{array}{c}\text { Carga Horária } \\
\text { Total }\end{array}$ \\
\hline 1968 & Prática de Ensino & $\begin{array}{c}60 \text { horas/aula no VIII } \\
\text { semestre. }\end{array}$ & 60 horas/aula \\
\hline $1975^{8}$ & $\begin{array}{c}\text { Prática de Ensino da área } \\
\text { de Estudo de Ciências }\end{array}$ & $\begin{array}{c}90 \text { horas/aula no VIII } \\
\text { semestre. }\end{array}$ & 90 horas/aula \\
\hline $1975^{9}$ & $\begin{array}{c}\text { Prática de Ensino de } \\
\text { Matemática }\end{array}$ & $\begin{array}{c}90 \text { horas/aula no VIII } \\
\text { semestre }\end{array}$ & 90 horas/aula \\
\hline 1987 & $\begin{array}{c}\text { Prática de Ensino de } \\
\text { Matemática I - II - III - IV }\end{array}$ & $\begin{array}{c}30 \text { horas/aula no V, VI VII e } \\
\text { VIII semestres. }\end{array}$ & 120 horas/aula \\
\hline $1998-$ & $\begin{array}{c}\text { Prática de Ensino de } \\
\text { Matemática I - II - III - IV }\end{array}$ & $\begin{array}{c}30 \text { horas/aula no V e VI } \\
\text { vemestre, } 60 \text { horas/aula no } \\
\text { VII semestre e 180 horas/aula } \\
\text { no VIII semestre. }\end{array}$ & 300 horas/aula \\
\hline $2000-$ & $\begin{array}{c}\text { Prática de Ensino de } \\
\text { Matemática I - II }\end{array}$ & $\begin{array}{c}\text { 126 horas/aula no VII } \\
\text { semestre e } 180 \text { horas/aula no } \\
\text { VIII semestre. }\end{array}$ & 306 horas/aula \\
\hline 2003 & Estágio Curricular \\
atual & $\begin{array}{c}\text { Supervisionado I - II - III - } \\
\text { IV }\end{array}$ & $\begin{array}{c}72 \text { horas/aula no IV semestre, } \\
90 \text { horas/aula no V semestre e } \\
126 \text { horas/aula no VI e VII } \\
\text { semestres. }\end{array}$ & 414 horas/aula \\
\hline
\end{tabular}

Com base nas entrevistas feitas com alunos que estudaram nas diferentes grades curriculares percebeu-se uma significativa modificação no estágio conforme a grade curricular era alterada. Inicialmente, eram observadas e ministradas aulas em instituições escolares do ensino básico (denominação atual). Depois, além de observações de aulas em uma instituição de ensino básico, passou a existir a aplicação de um projeto pedagógico. Por fim, com o aumento da carga-horária e modificações introduzidas por força de legislação, o estágio passou a compreender uma série de atividades que vão além de observação de aulas, da aplicação de projetos nas instituições escolares, bem como o desenvolvimento de aulas de efetiva docência. Nas atuais atividades, os alunos-mestres vivenciam o dia-a-dia de uma escola, participando de todas as ações desta, tais como: conselhos de classe, reuniões pedagógicas, reuniões de pais e de Associações de Pais e Professores (APPs), elaboração de materiais didáticos, além de atuarem no papel de professor junto a turmas de alunos em atividade de "lecionação" propriamente dita, com o acompanhamento do professor regente da classe e a orientação/supervisão do professor da Universidade, entre outros. Deste modo, o 
desenvolvimento deste rol de atividades propicia aos estagiários: condições de desenvolver uma visão global da escola de ensino fundamental e médio; vivenciar ações educativas e perceber a importância dessas de serem cuidadosamente planejadas; elaborar estratégias para a superação de obstáculos de aprendizagem e perceber a necessidade da aprendizagem continuada em programas de formação ou na troca de experiências com os seus colegas de profissão.

Com o aumento da carga-horária disponibilizada para a Prática de Ensino e a ampliação de sua ação, o aluno passa a ter um maior contato com as escolas e a sua realidade, o que é um fator muito importante para a sua formação docente, porque é no desenvolvimento das atividades nas escolas que o aluno irá vivenciar as conexões entre as matérias teóricas por ele aprendidas com a prática na unidade escolar. E é na sua ação que o estagiário adquire subsídios para se tornar um profissional capacitado, através da observação da prática pedagógica de outros professores e das reflexões que devem surgir a partir das práticas observadas e do próprio desempenho de sua atuação, pois

Observar não é invadir o espaço do outro, sem pauta, sem planejamento nem devolução e muito menos sem encontro marcado... Observar uma situação pedagógica é olhá-la, fitá-la, mirá-la, admirá-la, para ser iluminado por ela. Observar uma situação pedagógica não é vigiá-la, mas sim fazer vigília por ela, isto é, estar e permanecer acordado por ela, na cumplicidade da construção do projeto, na cumplicidade pedagógica. (FREIRE, 1992, p. 14)

Outro fator de relevância percebido no estudo das grades curriculares foi que a disciplina de Prática de Ensino sempre esteve presente no final do curso (no último ano ou nos semestres finais). Possivelmente isto ocorria por se acreditar que o melhor período para o desenvolvimento do estágio em unidades escolares seria aquele quando o aluno já possuía um bom domínio dos conteúdos a serem utilizados nas aulas de docência, bem como ter conhecimento dos métodos e estratégias de ensino que poderiam ser empregados para melhor entendimento dos assuntos estudados, obtidas nas disciplinas teóricas em sala na Universidade. Atualmente, as estratégias e métodos de ensino são abordados em disciplinas como Didática e Matemática Instrumental. Existem outras disciplinas pedagógicas como Psicologia da Educação, Políticas Públicas, História e Legislação do Ensino que auxiliam o aluno-mestre em sua prática pedagógica. Entretanto, se observa que, há ainda dissociação entre a teoria abordada nas disciplinas do curso e o estágio de Matemática desenvolvido nas escolas. Muitas vezes, percebe-se a existência de disciplinas que abordam as teorias de aprendizagem, mas estas não auxiliam o aluno no contato com problemas específicos, como a 
rejeição à Matemática que diversos alunos do Ensino Básico denotam, por exemplo. Como tratar deste problema?

Uma das formas de auxiliar o estagiário em problemas específicos à sua área de trabalho, é haver uma relação entre a teoria aprendida nas disciplinas e a prática vivenciada em sala de aula, pois como cita Piconez (1991, p.25)

a Prática de Ensino sob a forma de Estágio Supervisionado é, na verdade, um componente teórico-prático, isto é, possui uma dimensão ideal, teórica, subjetiva, articulada com diferentes posturas educacionais, e uma dimensão real, material, social e prática, própria do contexto da escola brasileira.

O estágio realizado é de grande importância, pois permite ao aluno conhecer a realidade das instituições escolares em que poderá vir a atuar no futuro. De acordo com Pimenta (1995, p.71) "Os estágios têm possibilitado às alunas conhecerem essa realidade, aprendendo o que está sendo realizado e como, e também o que não está e por quê." Com base nesses dados extraídos através da observação da prática de professores supervisores de estágio, os estagiários têm condições de fazer reflexões sobre a situação da educação atual, bem como ponderar sobre a prática pedagógica que pretendem adotar. É imprescindível esta articulação entre o conhecimento experimental e o teórico, uma vez que é preciso utilizar a teoria para refletir sobre a experiência, interpretá-la e atribuir-lhe significado.

\section{Algumas considerações}

Mudanças no currículo dos cursos de formação de professores em diferentes épocas evidenciam a tentativa de possibilitar uma formação inicial de qualidade ao futuro profissional da educação. E foi acreditando nisso que conselhos internos da Universidade Regional de Blumenau fizeram as diversas alterações descritas neste texto. Destaca-se como um dos fatores de importância deste trabalho, a realização do resgate histórico da prática de ensino no curso de Licenciatura em Matemática da FURB, fato este nunca antes documentado.

A organização curricular atual ainda sofre discussões e propostas de novas reformulações. O ideal seria que todas as disciplinas do curso de Matemática fossem consideradas de prática para a construção do futuro educador, pois "todas elas contribuem para a construção da práxis do educador e se encontram no limite entre sua formação inicial e sua prática pedagógica;" (GOULART, p.85, 2002). Todavia, há ainda disciplinas de cunho 
estritamente teórico, desvinculadas da prática pedagógica e do campo de ação do futuro professor de Matemática.

Espera-se que, com essas reflexões acerca do estágio supervisionado, possa-se chegar a um consenso de que todas as disciplinas de um curso de licenciatura devam levar em consideração que estão formando futuros profissionais da educação e que servirão como subsídio a esses novos educadores em sua prática pedagógica. Portanto, quanto mais focadas em reflexões nas melhorias no processo de ensino, mais capacitados serão os futuros profissionais.

\section{Referências Bibliográficas}

BARREIRO, I. M. F.; GEBRAN, R. A. Prática de Ensino e Estágio Supervisionado na Formação de Professores. São Paulo: Avercamp, 2006.

BRASIL. Lei de Diretrizes e Bases da Educação Nacional n 9394, de 20 de dezembro de 1996.

Conselho Nacional de Educação. Resolução n. 2, de 19 de fevereiro de 2002. Institui a duração e a carga horária dos cursos de licenciatura, de graduação plena, de formação de professores da educação básica em nível superior.

FREIRE, M. Observação, registro, reflexão - instrumentos metodológicos. Série Seminários. São Paulo: Espaço Pedagógico, 1992.

GOULART, S. M. A Prática de Ensino na Formação de Professores: uma questão (des)conhecida. Revista Universidade Rural. Série Ciências Humanas. Rio de Janeiro: Universidade Federal Rural do Rio de Janeiro. Vol.24 (1-2), jan./jun. 2002. p. 77-87.

MATTOS, L. A. A nossa revista. Escola Secundária. Rio de Janeiro: Ministério da Educação e Cultura, n.1, jun. 1957, p. 5-9.

PICONEZ, S. C. B. A Prática de Ensino e o Estágio Supervisionado: a aproximação da realidade escolar e a prática da reflexão. In: FAZENDA, I.C.A (org). Prática de Ensino e Estágio Supervisionado. Campinas: Papirus, 1991. p.15-38.

PIMENTA, S. G. O Estágio na Formação de Professores: Unidade entre Teoria e Prática? Cadernos de Pesquisa. São Paulo: Fundação Carlos Chagas, n. 94, ago. 1995. p.58-73.

SILVA, C. M. S. da. A Faculdade de Filosofia, Ciências e Letras da USP e a formação de professores de Matemática. In $23^{\mathrm{a}}$ Reunião Anual da ANPED, 2000, Caxambu. Anais da $23^{\mathrm{a}}$ Reunião Anual da ANPED, $2000 . \quad$ Disponível em: http://168.96.200.17/ar/libros/anped/1925P.PDF. Acesso em 31 ago. 2007.

TANURI, L. M. História da Formação de Professores. Revista Brasileira de Educação. São Paulo, n.14, p.61-88, 2000. 